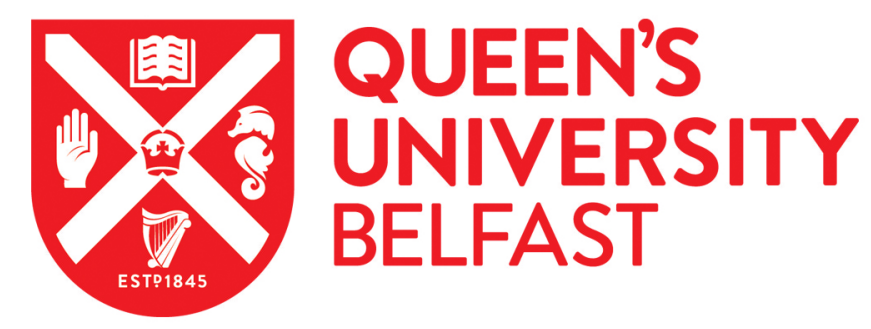

\title{
An Exploration of Protective Factors Supporting Desistance From Sexual Offending
}

de Vries Robbé, M., Mann, R. E., Maruna, S., \& Thornton, D. (2015). An Exploration of Protective Factors Supporting Desistance From Sexual Offending. Sexual Abuse: Journal of Research and Treatment, 27(1), 1633. https://doi.org/10.1177/1079063214547582

\section{Published in:}

Sexual Abuse: Journal of Research and Treatment

\section{Document Version:}

Peer reviewed version

Queen's University Belfast - Research Portal:

Link to publication record in Queen's University Belfast Research Portal

\section{Publisher rights}

Copyright 2018, Sage.

This work is made available online in accordance with the publisher's policies. Please refer to any applicable terms of use of the publisher.

\section{General rights}

Copyright for the publications made accessible via the Queen's University Belfast Research Portal is retained by the author(s) and / or other copyright owners and it is a condition of accessing these publications that users recognise and abide by the legal requirements associated with these rights.

Take down policy

The Research Portal is Queen's institutional repository that provides access to Queen's research output. Every effort has been made to ensure that content in the Research Portal does not infringe any person's rights, or applicable UK laws. If you discover content in the Research Portal that you believe breaches copyright or violates any law, please contact openaccess@qub.ac.uk. 


\title{
Protective factors supporting desistance from sexual offending
}

\author{
Michiel de Vries Robbé ${ }^{1}$, Ruth E Mann², \\ Shadd Maruna ${ }^{3}$ and David Thornton ${ }^{4}$
}

\begin{abstract}
This paper considers factors that support or assist desistance from sexual offending in those who have previously offended. Current risk assessment tools for sexual offending focus almost exclusively on assessing factors that raise the risk for offending. We reflect on the value of incorporating protective factors into the assessment process, and examine the available literature on this topic in order to propose a list of potential protective domains for sexual offending. We also describe some ideas about the mechanisms through which protective factors might work. Lastly we propose some ways in which treatment programs and research could take more account of protective factors predictive of desistance. Our aims are (1) to encourage those who assess and treat sex offending to introduce notions of desistance and strengths into their frames of reference, and (2) to inspire research investigations into the nature and influence of protective factors in enabling individuals to desist from further offending.
\end{abstract}

\section{Keywords}

sexual offending, desistance, protective factors 
${ }^{1}$ Van der Hoeven Kliniek, Utrecht, The Netherlands

${ }^{2}$ National Offender Management Service, London, England

${ }^{3}$ Queens University, Belfast, Ireland

${ }^{4}$ Sand Ridge Secure Treatment Center, Wisconsin, USA

\section{Corresponding author:}

Michiel de Vries Robbé, MSc, Department of Research, Van der Hoeven Kliniek, P.O. Box 174, 3500 AD Utrecht, The Netherlands

E-mail: mdevriesrobbe@hoevenkliniek.nl 


\section{Introduction}

Modern day risk assessment schemes tend to predict recidivism better than chance, but there is room for improvement. The major "third generation" assessment frameworks for assessing convicted sexual offenders (for example, STABLE, SRA/SARN, VRS-SO, SVR-20, RSVP) focus almost exclusively on factors that raise risk for recidivism. Consequently, Maruna and LeBel (2003) described the assessment of risks and needs as "deficit focused" and urged those in the criminal justice field to consider balancing such measurement with an assessment of individual strengths.

There are three reasons in particular why it may be important to consider strengths as well as risks in the assessment process. First, to do so could improve the predictive validity of our risk assessment tools. For instance, for forensic psychiatric patients convicted of violent offending, De Vries Robbé, De Vogel and De Spa (2011) found that violent recidivism was predicted more accurately when protective factors were added to the risk assessment. The same effect was found for the prediction of recidivism in patients with a history of sexual offending (De Vries Robbé, De Vogel, Koster, \& Bogaerts, submitted).

Second, a one-sided focus on risk can lead to over-prediction of violence risk, and poor risk management and treatment planning. Rogers (2000) argued that risk-only evaluations are inherently inaccurate and implicitly biased, often resulting in negative consequences to forensic populations. In particular, over-prediction (i.e., too many false positives) can lead to pessimism among therapists and unnecessarily long treatment or overly restrictive risk management, which are costly for both society, in terms of financial burden, and for the individual in terms of limited liberties (Miller, 2006).

Third, deficit-focused assessments can be stigmatizing for criminal justice clients. In particular, research by Attrill and Liell (2007) among prisoners and ex-prisoners emphasized the feelings of unfairness of the assessors' focus on risk to the exclusion of any recognition for positive accomplishments. For example, one prisoner in their study reported his view that, “From my experience risk assessment isn't fair as it's just pure 
negatives that people look at, not positives". Such testimony raises the possibility that the emphasis on risks found in most current assessment processes will have a negative impact on the relationship between the assessor and the assessee, and consequently perhaps on the rehabilitation process itself.

These risky aspects of risk assessment may be offset by paying more than lip service to the concept of protective factors in assessment work. By this term, we mean factors that enable or assist desistance from (sexual) offending among those that have already offended. In the criminology field, some work has focused on the assessment of protective factors (e.g., Herrenkohl et al., 2003) or individual "strengths" as a way of complementing the deficit-driven focus on risks and needs (e.g., Maruna $\&$ LeBel, 2003). Others have sought to subtly shift the focus away from assessing predictors of recidivism to those factors associated with successful desistance from crime (e.g., Farrall, 2004; McNeill, 2006; Robinson \& Shapland, 2008).

Before protective factors can be fully incorporated into sexual offending assessment frameworks, however, we need to (1) identify potential protective factors from exploratory research and the theoretical literature; (2) build theoretical models to explain how the identified protective factors reduce risk; (3) articulate and systematically collect data on these variables and examine their relationship with recidivism; and (4) build and validate tools for the assessment of protective factors for sexual violence.

The present article seeks to complete the first of these steps i.e., examine the existing literature to identify and propose potential protective factors. We will also briefly discuss the mechanisms by which protective factors may reduce the impact of risk factors, or operate independently from risk factors, to enable successful desistance.

\section{Conceptualizing Protective Factors}

A starting point in seeking to define protective factors might be to mirror accepted definitions of risk factors (e.g., Andrews \& Bonta, 2006) by stating 
that a protective factor is a feature of a person that lowers the risk of reoffending. In addition to internal, psychological features, there is a question about whether or not external, environmental or circumstantial features of an individual's life situation could also be considered to be protective factors. Certainly, criminological research into desistance indicates that an ex-offender's social situation is an important factor associated with desistance. In fact, some desistance researchers would argue that external factors are more important than internal ones (for a discussion, see LeBel, Burnett, Maruna, \& Bushway, 2008). In the case of sexual offending in particular, restrictive external circumstances are frequently imposed upon the individual against his preference, such as incarceration, residency restrictions, social isolation, and restricted employment opportunities. If these external circumstances are guided by empirical evidence, they can be an important part of risk management processes to create more protective environments. Therefore, we believe that the definition of a protective factor should encompass social, interpersonal and environmental factors as well as psychological and behavioral features.

In pursuit of an approach to risk reduction based on building protective resources, we could profitably further differentiate between static/unchangeable protective factors (e.g., secure attachment in childhood) and those that are behavioral or otherwise potentially changeable. In line with a recent theory of risk factors (Mann, Hanson, \& Thornton, 2010), we also suggest that it is helpful to distinguish between the protective factor as an underlying propensity (psychological or personality characteristic) and observable manifestations of that propensity. For example, holding down a job may be a manifestation of several underlying propensities (e.g., work ethic, plus self-discipline, plus ability to manage social relationships) which together enable stable employment, along with external factors (e.g., economy, employment discrimination). In another example, the underlying propensities of secure adult attachment and good social skills may be manifest in generally wellfunctioning intimate relationships. 
Some researchers (e.g., Farrington, 2003) have divided the factors associated with positive desistance outcomes into two categories depending on whether the positive factor has a direct influence on desistance irrespective of risk level (termed promotive factor) or whether the positive factor moderates the impact of risk factors (i.e., has greater risk reducing effects for those people deemed to be at high-risk of offending than for those deemed to be low-risk (the more precise use of the term protective factor or resilience). Ullrich and Coid (2011) did not find indications that protective factors have different effects at different levels of risk, while Lodewijks, De Ruiter and Doreleijers (2010) found proof for a buffering or mitigating effect of protective factors on risk factors in adolescent samples. As we are equally concerned with both types of positive factors, and as the sexual offending protective factor literature is still in its infancy, these distinctions are probably too fine for the current state of knowledge, and so we use the term protective factors here as a general term to refer to both types.

To develop the definition further, we propose that protective factors must exist as definable propensities or manifestations thereof in their own right, rather than being no more than the absence of a risk factor. Accordingly, it should be possible to define individual protective factors without the use of negatives. To illustrate, "capacity for intimacy" would meet this condition, but "lack of hostility" would not. Put another way, some protective factors are likely to be the opposite of risk factors, a proposal which we explore in more detail below, but in this argument we draw a clear distinction between the opposite of a risk factor and the absence of a risk factor.

Additionally, protective factors and risk factors can conceivably cooccur in the same domain. That is, even protective factors that are the opposite, or "healthy pole", of risk factors are not necessarily mutually exclusive entities from the risk factor. An example in which protective and risk factors can co-occur is in the domain of social influences. Negative social influences are generally considered a risk factor, while positive social influences are considered a protective factor. However, it is quite possible 
for individuals to have both negative and positive social influences in their lives, that is for strengths and risk factors to co-exist even though they seem like opposites. For example, a person could both belong to a drug-using social group and, separately, attend university classes with students learning engineering. A single measure of social influences "positive or negative?" would not capture this common complexity. A risk assessment tool which poses strengths as the opposites of vulnerabilities and measures both ends of risk domains simultaneously is the Short-Term Assessment of Risk and Treatability (START; Webster, Martin, Brink, Nicholls, \& Middleton, 2004). However, despite good results for predicting non-violence with the strengths scale, no incremental predictive validity over vulnerabilities has yet been reported (e.g., Braithwaite, Charette, Crocker, \& Reyes, 2010; Chu, Thomas, Ogloff, \& Daffern, 2011; Viljoen, Nicholls, Greaves, De Ruiter, \& Brink, 2011).

Finally, protective factors can be the result of social development factors (families, peers, communities) as well as from biological and psychological maturation. As with risk factors (see Ward \& Beech, 2005) there may well be neural mechanisms associated with protective factors, possibly originating from pre-natal or peri-natal conditions or early childhood experiences. Such mechanisms need to be uncovered and understood, in order to assist treatment providers' efforts to strengthen an individual's protective factors, or provide him with prosthetics to compensate for under-developed or 'missing' protective factors. Although the medical analogy is far from ideal, we use the term prosthetics here to refer to 'artificial' (or coached) protective factors that effectively compensate for the absence of 'organically' occurring protective factors. Examples would be structured problem solving skills or learned ways of expressing feelings assertively. Psychiatric medications (e.g., SSRIS or antilibidinal medications) could be considered to be prosthetic protective factors if they have the effect of reducing the intensity of sexual drive or enhancing sexual self-control.

\section{Identifying Protective Factors for Sexual Offending}


Mirroring the accepted definition of a risk factor for sexual offending, a protective factor should be empirically related to desistance from sexual offending. A stringent standard, equivalent to the standard set for a risk factor (see Mann et al., 2010), would require at least three separate studies, when meta-analytically integrated, to demonstrate that the presence of the protective factor was associated with lower reconviction rates. However, as the literature into protective factors for sexual offending is in its infancy with few empirical studies yet reported, there is a minimal evidence base to consider (see also Laws \& Ward, 2010).

Moreover, there may be additional ways of identifying protective factors besides reconviction studies. After all, desistance research starts from a different point than treatment research by putting the individual (not the program) at the centre of the change process (see Maruna, 2011). Rather than asking "what works" and comparing the reconviction rates of treatment and control groups, desistance studies ask how change works and seek to identify those factors that support the individual in his or her efforts to maintain desistance (for reviews see Laub \& Sampson, 2001; Farrall \& Calverley, 2005). Therefore, in this paper we also draw on qualitative and quantitative desistance studies to identify potential protective factors in sexual offending. The hope is that future evaluation research might empirically test the protective factors proposed in this paper and complement the understanding of desistance from sexual offending. Additionally, it would be valuable if sexual offending research were to differentiate between protective factors associated with desistance from general or violent offending and protective factors associated specifically with desistance from sexual offending, as these may not necessarily be the same factors.

We will consider a variety of sources of ideas about what psychological propensities or sociological circumstances might aid desistance from sexual offending. Our literature review concentrates on three areas (1) the sex offending risk factor literature, to consider when the opposing / healthy end of a risk domain could be considered protective; (2) the desistance literature in criminology; and (3) the content (and validity) 
of existing measures of protective factors that have been applied in sex offending assessment. The aim is to integrate the findings from these diverse sources to create a list of potential protective factors for sexual offending.

\section{Protective Factors as the Opposite of Risk Factors for} Sexual Offending

As already discussed, it seems likely that often protective factors and risk factors would be two sides of the same coin. That is, the unhealthy pole of a continuum represents a risk factor (e.g., offence-supportive beliefs) while the healthy pole represents a protective factor (e.g., in this example, beliefs supportive of respectful and age-appropriate sexual relationships). As proposed earlier, protective factors must exist as definable propensities rather than being no more than the absence of a risk factor. However, in some cases, risk factors are formulated as the absence of a healthy propensity or skill (e.g., "poor problem-solving skills") so the presence of the healthy propensity (in this example, "good problem-solving skills") could be considered a protective factor.

Table 1 shows the risk factors for sexual offending which have the strongest empirical support (see Mann et al., 2010, for an account of the evidence base for these factors) and their suggested corresponding positive poles, i.e., the healthy propensities of these risk factors.

TABLE 1 HERE

\section{Protective Factors in the Desistance Literature}

'Desistance from crime' has become a dominant area of research activity within criminology over the last 20 years (see Farrall \& Calverley, 2005). The concept of desistance relates to the process of abstaining from crime after repeated or habitual engagement in criminal activities (Maruna, 2001). Desistance processes often involve key turning points or disorienting life 
episodes (Laub \& Sampson, 2001), but desistance is not a single moment or event in a person's life. Instead, desistance is widely understood as a longterm maintenance process involving a slow recognition of the need to change, motivational fluctuation, and possible false starts followed by lapses or relapses. By changing the focus of inquiry from investigating why some ex-prisoners "fail" (or re-offend) and instead trying to understand how and why some individuals succeed or "go straight", desistance research has opened up new understandings in criminology with distinct implications for assessment and treatment practice.

General desistance factors. The factors identified by the criminological literature for desistance from general criminal offending may also be relevant to sexual offending (Laws \& Ward, 2010). For example, ageing, stable employment, marriage, sobriety, lack of stress, and good mental health, have all been found to have a protective effect on criminal behavior (Laub \& Sampson, 2001). Moreover, research with ex-prisoners suggests that long-term, persistent offenders tend to lack a sense of hope or feelings of agency (Maruna, 2001; Zamble \& Quinsey, 1997). On the other hand, reformed ex-prisoners are characterized by hope and optimism: they seem to maintain an overly optimistic sense of control over their future and strong internal beliefs about their own self-worth and personal destinies (Burnett \& Maruna, 2006; LeBel et al., 2008; Maruna, 2001). Desisters also seem to embrace change-enhancing cognitive patterns: consistent patterns of cognition that encompass the ability to evaluate one's behavior and learn from one's mistakes (Maruna, 2001). Arguably, one potential indicator of this willingness to change is the individual's persistence with a course of intervention to change risk-relevant behavior. Additionally, desisters seem to possess a sense of achievement and accomplishment (see Maruna \& LeBel, 2003). Making meaningful contributions to one's community or family can lead to grounded increments in self-esteem, feelings of meaningful purposiveness, and a cognitive restructuring toward responsibility for young people in trouble with the law (Toch, 2000). Such successful achievements can predict successful desistance (LeBel et al., 2008) or abstinence from 
crime (Uggen \& Janikula, 1999). Lastly, the desistance literature has established the importance of moving away from groups of delinquent peers (Warr, 1998) and establishing meaningful intimate relationships (Laub \& Sampson, 2001). The latter also being the opposite pole of "lack of emotional intimacy with others", which is a strongly evidenced risk factor for sexual offending (Mann et al., 2010).

Sex offending desistance factors. To date studies of desistance from sexual crimes are few (see Laws \& Ward, 2010). Farmer, Beech and Ward (2012) studied the self-narratives of individuals convicted of child molestation who had apparently desisted from offending, comparing them with individuals who were thought to be still actively seeking opportunities to offend. Several factors differentiated the desistance group from the active group. The desisters appeared to have an enhanced sense of personal agency; had a stronger internal locus of control; were consistently more able to find positive outcomes from negative events; identified treatment as having provided them with a turning point; and, most strikingly, seemed to have found a place within a social group or network. They described belonging to three particular types of social groups or communities: family, friends and church. In contrast, the "active" or at-risk group all described themselves as socially alienated or isolated from others (Farmer et al., 2012).

\section{Measures of Protective Factors}

In this section, we review structured assessment tools that have incorporated protective factors into their frameworks. Our search yielded only one such tool designed specifically for (juvenile) sexual offenders (the AIM-2) and one tool designed for broader criminal populations that has specifically been tested with sexual offenders (the SAPROF). A list of the protective factors assessed by the AIM-2 and the SAPROF is shown in Table 2 below.

TABLE 2 HERE 
AIM-2. Building on an earlier Protective Factors Scale (Bremer, 2001), the AIM-2 (Print et al., 2007) is a tool designed to guide the assessment of young people (aged 12 to 18 ) who are known to have sexually abused another person. The factors assessed are grouped into four domains: developmental issues, family issues, current environment and offencespecific issues. The tool includes 24 protective factors (which are termed strengths or resiliencies) as well as 51 risk factors. The AIM-2 manual articulates similar clinical reasons for assessing strengths to those we described earlier, such as wishing to avoid negative labeling, and wishing to promote a positive focus in work with young people. The AIM-2 assessment yields two profiles: a Concerns profile and a Strengths profile, which form the basis for an evaluation report and/or a treatment plan. The model theorizes that protective factors "present the possibility of being able to reduce the trait level of problems" (Griffin, Beech, Print, Bradshaw, \& Quayle, 2008, p. 216).

At present, AIM-2 is supported by one research study (Griffin et al., 2008). This study involves 70 adolescents convicted of sexual crimes, seven of whom recidivated in a new contact sexual offense. Chi-square analysis indicated that fifteen items distinguished the recidivists from the nonrecidivists, eight of which were strengths items (above average intelligence, positive talents / leisure interests (analyzed separately in this study), positive attitudes from significant adults, positive emotional coping from significant adults, at least one emotional confidant, positive evaluations from work/education, positive relationships with professionals). These items were then summed into a scale which made a significant independent contribution to recidivism prediction (area under the receiver operating characteristics curve $(A \cup C)=.94)$. While this result is unsurprising, given that these were the items that differentiated the two groups, it was also noted that a high score on the strengths scale acted as a protective factor even for those with a high score on the concerns scale. All the recidivists had high concerns scores and low strengths scores. Only seven of the 63 non-recidivists had a high concerns score, and only one of these seven also 
had a low strengths score. Whilst there were several important limitations to this juvenile study (particularly the small sample size) the results tentatively support the initial hypothesis that protective factors ameliorate risk of sexual re-offending.

\section{SAPROF. The Structured Assessment of Protective Factors for} violence risk (SAPROF; de Vogel, de Ruiter, Bouman, \& de Vries Robbé, 2009; $2^{\text {nd }}$ Edition 2012) is designed to assess protective factors in adults convicted of any violent crime (including sexual). The SAPROF was developed in the Netherlands as a structured professional judgment (SPJ) protective factors assessment tool to form a positive supplement to the HCR-20/HCR:V3 or related SPJ risk tools. It contains 17 protective factors, which are mostly dynamic in nature and divided into 3 scales: internal factors, motivational factors and external factors (similarly to psychological, behavioral and environmental features). Each factor is provided with a rationale describing its empirical background, which largely relies on general violent crime research and to a lesser extent incorporates research on sexual offending. After completing the scale, the assessor has the option to mark factors as critical for the overall protection or for treatment planning ('keys' and 'goals') and makes a "final protection judgment”. The results from the assessment are intended to be integrated with results from a risk tool to come to an overall final judgment on the level of risk, which incorporates both the present risk- and protective factors.

Previous results with forensic psychiatric patients convicted of violent offending showed good predictive validities for the SAPROF as well as incremental value of the protective factors over risk factors (De Vries Robbé et al., 2011). The first study that concentrated on patients convicted of sexual offending was recently carried out by De Vries Robbé and colleagues (submitted). In this study the predictive validity of the protective factors in the SAPROF for non-recidivism among 83 discharged treated sexual offenders was analyzed. The total score of the 17 protective factors was significantly predictive of no new convictions for any (including sexual) violence for short-term (1-3 year) as well as long-term (15 year) follow-up 
$(A U C=.83-.74)$ as was the final protection judgment $(A U C=.79-.66)$. When only sexually violent recidivism was used as outcome measure, the SAPROF total score was the only consistently significant predictor $(A U C=.93-.71)$. However, especially for short-term follow-up the base-rate of sexually violent recidivism was very low. Incremental predictive validity was found when the assessments included both risk- and protective factors. The incremental value of including protective factors was demonstrated for general violent re-offending as well as for sexually violent re-offending. The best predicting protective factors for abstaining from violence were Coping, Self-control, Motivation for treatment and Attitudes towards authority. The first three of these were also significant predictors of no sexually violent reconvictions. The items Professional care, Medication, Work and Financial management also showed decent individual predictive values for either violent or sexually violent recidivism.

Prospective clinical studies into the predictive validity of the protective factors in the SAPROF for no violent incidents during treatment of forensic psychiatric patients (follow-up 12 months) also showed good results for those patients convicted of sexual offending $(A U C=.81)$ (de Vries Robbé \& de Vogel, 2012). Prospectively, the strongest desistance predicting factors for the sexual offending sample were Coping, Leisure activities, Attitudes towards authority and Network. Additional studies into the predictive validity of the SAPROF for different categories of sexual crime types are currently being conducted.

The protective factor measures that have been developed so far show some promising results. Nevertheless, the research samples are still small and replication of these findings is essential. The tools vary in terms of the extent to which they measure variables with similar properties. For example, if the lists of protective factors included in the various measures are examined in the light of the propensity/manifestation distinction, it can be seen that the scales include both types. For instance, many of the dynamic AIM-2 items seem to describe manifestations of an underlying propensity to form positive relationships with friends, family and professionals. However, overall (and perhaps unsurprisingly given that 
research in this area is still in its infancy), there are easily observable themes to the items within the different scales.

\section{Proposed Protective Factors for Sexual Offending}

We propose that the various literatures discussed in the preceding review can be summarized into eight "protective domains" that could be hypothesized to assist desistance from sexual offending. Table 3 provides an overview of the protective factors derived from the preceding review and their relationship to the proposed protective domains. The factors are categorized by source: (1) the healthy poles of sexual violence risk domains; (2) desistance factors for sexual offending; and (3) protective factors for sexual offending derived from empirical studies on measures of protective factors.

\section{TABLE 3 HERE}

(1) Healthy sexual interests. This domain refers to a propensity to prefer sexual relationships with consenting adults co-existing with a moderate intensity sexual drive. Individuals with protective factors in this domain are likely to show a balance between a desire for sexual fulfillment and a desire for other types of fulfillment. They will have adequate sexual knowledge and beliefs that support age appropriate and consenting relationships. This domain is construed as the healthy poles of two, well-established sexual offending risk factors: Sexual preference for consenting adults and Moderate intensity sexual drive. Additional evidence for healthy sexual interests may be found in the presence of Attitudes supportive of respectful and age-appropriate sexual relationships (the healthy pole of the risk factor Offence-supportive attitudes).

(2) Capacity for emotional intimacy. This domain refers to a propensity to form and maintain emotionally close and satisfying relationships with other adults. Individuals with protective factors in this domain will most likely have a Trustful and forgiving orientation to others (healthy pole for the risk 
factor Grievance/hostile attitude to others), a Preference for emotional intimacy with adults rather than children (healthy pole for the risk factor Emotional congruence with children), and the ability to communicate effectively. The most obvious manifestation of this propensity is that the individual has, or has had, long-lasting and emotionally stable intimate relationships with adult partners (e.g., the item Intimate relationship in the SAPROF and the risk factor healthy pole Capacity for lasting emotionally intimate relationships with adults). The healthy poles Positive attitudes towards women, Honest and respectful attitudes and Empathy all reflect underlying personality traits which enhance capacity for emotional intimacy.

(3) Constructive social and professional support network. This protective domain refers to the capability of forming constructive relationships with other adults, both socially and with persons in professional support and authority roles. Individuals with protective factors in this domain will have a law abiding social network. This is represented in the AIM-2 item At least one emotional confidant, in the SAPROF item Network, in the desistance factor Place within a social group or network, and in the risk factor healthy pole Law-abiding social network. Additional support is provided by AIM-2 items Significant network members have positive attitudes and Significant network members have positive emotional coping. Individuals with protective factors in this domain would also have meaningful relationships with professionals (AIM-2 item Positive relationships with professionals, SAPROF items Motivation for treatment and Professional care, and desistance factor Treatment as turning point), and a positive attitude to authority (SAPROF item Attitudes towards authority, also the risk factor healthy pole Acceptance of rules and supervision). The risk factors healthy poles Honest and respectful attitudes and Empathy reflect underlying traits which facilitate the development of a constructive social and professional support network. This domain also encompasses all four of the factors found by Ullrich and Coid (2011) to predict non-violent outcomes for those 
convicted of sexual and violent crimes (social support, emotional support, spare time spent with family and friends, and closeness to others).

(4) Goal directed living. This protective domain refers to the capacity to set goals and direct daily activities so that progress can be made towards those goals. Individuals with protective factors in this domain will show effortful, positive, goal directed behaviors (the risk factor healthy pole Self-control), will have Enhanced sense of personal agency and Stronger internal locus of control (both desistance factors), and will show good self-discipline (SAPROF items Self-control and Financial management).

(5) Good problem solving. This protective domain refers to the capacity to manage life's daily problems without becoming overwhelmed or resorting to anti-social or avoidance techniques to regain control. Such a propensity is reflected by the risk factor healthy poles Functional coping and Effective problem solving skills and is also reflected in SAPROF item Coping. The AIM2 item Above average intelligence may reflect underlying abilities for good problem solving.

(6) Busy with employment or constructive leisure activities. This protective domain refers to the propensity to live a life dominated by constructive and rewarding activity and ideally also a sense of intrinsic satisfaction and accomplishment. Employment is the most obvious protective factor, well established as such in the general desistance literature and reflected in the SAPROF item Work and the AIM-2 item Positive evaluations from work/education. Equal results could be obtained from engaging in personally meaningful leisure or social activities such as sports, social hobbies, or caring for others (SAPROF item Leisure activities and AIM-2 item Positive talents / leisure interests).

(7) Sobriety. This protective domain refers to the abstention from drug or alcohol misuse. It is an established protective factor in the general desistance literature. An indicator for the likelihood of sobriety intentions 
to succeed is the SAPROF internal item and risk factor healthy pole Selfcontrol.

(8) Hopeful, optimistic and motivated attitude to desistance. This protective domain refers to the optimistic change-enhancing cognitive patterns identified in the general desistance literature. Individuals with protective factors in this domain are likely to Find positive outcomes from negative events (desistance factor), are motivated to work with treatment providers or other helping agencies (SAPROF item Motivation for treatment) and see Treatment as a turning point (desistance factor). The SAPROF item Medication use may provide additional evidence of desistance motivation.

In summary, eight protective domains are proposed based on being healthy poles of well-established sexual offending risk domains, being desistance factors for sexual offending, and/or being protective factors from existing risk-assessment tools proven to be valuable in predicting sexual and violent offending. We propose that each domain represents an underlying propensity, which may be pre-existing, may have developed as the individual reflects on his life and the consequences of his offending, or may have developed as a prosthetic through a rehabilitative intervention. The presence of each propensity may be observed in a range of possible behavioral indicators, or manifestations of the propensity.

\section{Mechanisms of Protective Factors}

If the protective factors proposed here do indeed reduce risk for recidivism in individuals who have sexually offended, it is necessary to articulate the mechanism through which they do this. It is also necessary to articulate an account of how risk and protective factors could co-exist, and what it means for risk assessment if they do. At this stage we will offer some preliminary thoughts about the mechanisms by which some of the proposed protective factors may assist a person to desist from offending. It is evident, however, that more detailed theoretical work is needed in this area; as is the collection of data to validate these proposals. 
Serin and Lloyd (2009) noted that desistance from crime is part of a larger trend of psychological, behavioral and social adjustment - just as offending is multiply determined, so is desistance. In their theory, the main mechanism underlying desistance is "reductions or reversals of dynamic risk factors" (p. 353) - which, given that many protective factors are the opposite of risk factors, could also be stated as "development and strengthening of protective factors". However, Serin and Lloyd also noted that such shifts in criminogenic needs are not the full story - the process of desisting from crime is not simply the reversal of the process of entering it and speculated that "attitudes associated with desistance are distinct from risk factors" (p. 355) and may develop from "taking stock" of the costs of crime. Some of the suggested protective domains above are highly congruent with this model of change.

Additionally, we propose that the Theory of Reasoned Action (TRA, Fishbein \& Azjen, 2010; supported by over one thousand empirical studies of multitudinous applications) can act as an over-arching framework to understand the way in which protective factors enable desistance. Indeed, the TRA, although not explicitly referenced in Serin and Lloyd's (2009) model of desistance, has clearly influenced their theory. Research into the TRA has determined that the strongest predictor of behavior is behavioral intention which is predicted in turn by three key elements: behavioral beliefs (the attitude that the individuals holds towards the behavior in question), normative beliefs (what the individual believes that salient others think about the behavior in question) and control beliefs (the extent to which the individual believes they can control the behavior in question; akin to self-efficacy). The more strongly an individual has a favorable attitude towards a certain behavior, perceives pressure from others to perform the behavior, and believes he can perform the behavior, the stronger will be his behavioral intention and the more likely he is to perform the behavior. In terms of offending, this could work to enable either sexual offending or desistance. Hence, in relation to offending the TRA would predict that successful desisters would have negative personal attitudes towards offending, strong social networks that disapprove of crime and 
confidence in their ability to desist. These elements can be seen in most of the proposed protective domains for sexual offending.

The Good Lives Model of offender rehabilitation was developed as a strengths-based elaboration on the RNR model by Ward and colleagues (Ward \& Brown, 2004; Ward \& Mann, 2004). This approach is based on the assumption that human behavior is motivated by Goods enhancing wellbeing and personal functioning. Providing pro-social routes to attaining Goods, may offer positive behavioral alternatives to offending behavior. For example, as the establishment of a romantic intimate relationship may increase the opportunity to achieve sexual Goods through consensual and reciprocal sexual activity, this will reduce the likelihood of attempting to find sexual gratification through inappropriate strategies like rape. According to the Good Lives Model, one of the best ways to lower offending recidivism rates is to equip individuals with the tools to live more fulfilling lives. Sense of belonging, achievement and hope may be accomplished through employment, leisure activities and social integration, which provide for positive and functional/desirable alternatives to criminal activity. This approach is in line with the Solution-Focused Treatment model (SFT; De Jong \& Berg, 2008), in which individuals are encouraged to explore and elaborate on positive personal goals (Wand, 2010).

The neuroscience of attachment could also offers some possible explanations on the working of social protective factors. Coan (2010) proposed that adults in attached relationships evidence reduced threatrelated brain activity, probably because two individuals who are attached assist each other with emotional regulation. Furthermore, securely attached adults have less difficulty in regulating threat-related negative thoughts and seem less sensitive to potential loss or danger than individuals who suffer from insecure attachment styles, showing corresponding differences in brain activation. Thus, development of more stable and trusting relationships may enhance healthier neurological functioning. Chemical imbalances may also influence neurological functioning and may be able to benefit from medication intake. Medication could have a balancing effect on for example 
sexual drive, psychotic symptoms, depression or impulsivity, which could have a direct or indirect relationship with sexual offending.

Besides promoting desistance through positive changes in cognitions, behavior and activities, protective factors can also offer support through environmental change. Changes in a person's environment greatly influence the likelihood of offending: restrictive conditions like court orders or ultimately detention reduce the opportunity to offend; supervision from parole officers or supervised housing provides extrinsic motivation to not recidivate; and support from therapists, case managers or social network members may provide emotional and practical support and motivation to do well and desist. This importance of environmental factors is in line with control theory (Cochran, Wood, \& Arneklev, 1994), which proposes that external factors such as religion can be regarded as an important socializing institution for promoting law abiding behavior.

At the start of rehabilitation efforts, external factors may offer invaluable protection as the individual has not yet been able to develop personal strengths and work through important risk factors. The provision of external factors may in fact enable more internal psychological protective factors to develop (such as Coping and Self-control) by creating a "safe" environment which is less influenced by temptations and triggers. Rehabilitation back to society should offer practice ground for developing more internal strengths and better societal integration. During this rehabilitation process environmental protection is gradually replaced by personal capabilities, social support and intrinsic motivation to desist (De Vogel et al., 2012, p. 28). Although sometimes environmental protective factors may need to provide life-long assistance, ideally these environmental factors are eventually no longer necessary (i.e. treatment efforts can be finalized and/or court orders terminated).

\section{Building Protective Factors in Treatment}

Protective factors that do not exist naturally may be teachable but they need to embed and to manifest over time before they will protect against offending. There are several ways in which current treatment paradigms 
could adapt to increase their focus on protective factors. Strengths-oriented assessment and treatment is more appealing to the participant, and should firm up a behavioral intention to desist. Positive reframing may increase responsivity and make treatment more effective and efficient. While these are good arguments to give a greater focus on protective factors in treatment design, protective factors should be targeted in addition to risk factors rather than replacing them. Well-established risk factors should still define essential targets of any treatment program, in line with the RNR model.

The aim of psychological treatment for sexual offending could be conceptualized as attempts to develop prosthetic skills that bolster the individual's strengths in areas where he or she has psychological, behavioral or environmental deficits. For instance, treatment may teach participants to consciously follow a sequence of steps needed to solve life problems. Most people have no need to learn such a sequence because they already solve most of their day-to-day problems reasonably effectively. But for those who struggle to cope with the daily challenges of life, or when an individual faces a particularly challenging problem, knowledge of problem-solving steps has a prosthetic effect. Intervention programs also aim to build prosthetic skills when they teach such principles as mindfulness, decisionmaking steps, progressive muscle relaxation (a prosthetic process to reduce physiological arousal associated with anger), intimacy or social skills (prosthetic processes to enable more satisfying intimate relationships) or calming self-talk (a prosthetic process to reduce the ruminative cognitive component of anger).

In addition to prosthetic skills, rehabilitative interventions could also provide prosthetic protection in itself. For instance, external supervision from the treatment team, active support from the social network, daily structure and life-fulfillment from a job, social integration from social leisure activities, and renewed chemical balance from medication can all provide vital prosthetics for deficits in skills and destabilizing psychopathological traits. External, environmental or situational factors can be important protectors for all individuals treated or incarcerated for sexual 
offending, even those with high-risk profiles or patients whose risk reducing treatment efforts have shown little success.

There are three ways in which protective factors could be embedded into treatment programs. First, as argued above treatment designers could think of some of the content of treatment as "providing prosthetic skills and prosthetic external or environmental protectors". Psycho-educational modules within treatment programs often focus on improving selfmanagement and developing personal and interpersonal skills. The provision of medication to reduce sexual drive can be conceptualized as an external prosthetic. The availability of continued support from professional care, as well as the development of daily structure and life-fulfillment from education or employment, can be considered environmental prosthetics. As these skills, external factors and supportive environments become embedded into the client's repertoire, they should take on a protective effect. Focusing on building these prosthetics in treatment needs to go hand in hand with encouraging acceptance, insight, motivation and ability to employ the prosthetics and to make them become manifest over time. As such, these prosthetics should be viewed by treatment providers as promising success factors for desistance from sexual offending.

Second, treatment providers could adopt the general therapeutic ethos that treatment is intended to assist clients in their own journey to become more functional, satisfied, and connected human beings. This is a similar approach to that prompted by the Good Lives theory of offender rehabilitation. So for example, if a rape was in part a poorly chosen strategy to meet an unfulfilled intimacy need, a strengths-orientated treatment program would provide the skills to develop more functional and successful intimate relationships (as many treatment programs currently do). Protective-oriented programs aim to build resources rather than strip away risk factors.

Third, treatment providers could adopt a conscious strategy to reinforce protective factors. The "what works" principles of the RNR Model suggest that positive reinforcement of good behaviors should outweigh punishments of negative behaviors by a $4: 1$ ratio (Gendreau, Smith, \& 
French, 2006). Moreover, research in the substance abuse field by Petry, Tedford and Martin (2001) suggests that prosocial activity reinforcement is more effective than reinforcement that is purely directed toward the absence of negative behaviors (e.g., drug abstinence). They found that prosocial activity reinforcement may result in improvements in psychosocial functioning (employment, medical, family problems) that are not apparent when drug abstinence alone is reinforced.

\section{Conclusions and Implications for Research}

De Ruiter and Nicholls (2011) describe the study of protective factors as a new frontier in forensic mental health which needs to be explored in order to increase our knowledge on what works in risk prevention. We know very little about what those who have offended sexually value, what makes them happy, and what skills and strengths are related to their desistance from offending. The desistance literature is very sparse in relation to sexual offending. We therefore urgently need desistance studies that focus on sexual offending. We also need to further investigate whether and to what extent assessments of protective factors increase the accuracy of sexual violence risk assessment. We may need to create new structured schemes for identifying protective factors specifically for sexual reoffending, and use these routinely, so that we can collect and compare data from samples of individuals convicted of different types of sexual crimes and relate these to risk focused tools, treatment efforts and recidivism outcome.

The SAPROF seems to be a good starting point for this as it encompasses many of the proposed protective domains described above. Healthy sexual interests is the only protective domain which we have proposed as exclusively relevant for sexual offending and has not been incorporated in the SAPROF. The other seven domains should be considered as general protective domains and are represented in several of the factors in the SAPROF. These factors can all be described as "dynamic improving", meaning that potentially they could change for the better, serve as positive goals for treatment efforts and be valuable factors for evaluating treatment 
progress. Large-scale prospective follow-up research is needed to be able to validate their assumed potential for desistance from sexual offending.

In this article we have argued for a greater focus on protective factors in assessment, research and practice. In recent years, those who work in sexual offender treatment have shown an extensive interest in the Good Lives Model of offender rehabilitation. As a strengths-based approach to understanding and treating sexual offending this has played an important role in enabling treatment practice to move away from the more confrontational approaches that were typical in the 1980s. However, the field of sexual offending risk assessment still employs a predominantly deficit-focused approach. It takes some years to collect and analyze the data necessary to validate new risk prediction items or scales. We therefore believe that it is necessary for those engaged in sexual offender assessment to incorporate the notion of protective factors into their research and practice as a matter of urgency. A sea change in our approach to risk assessment could yield multiple benefits, both to treatment clients and to society. 


\section{References}

Andrews, D. A., \& Bonta, J. (2006). The psychology of criminal conduct $\left(4^{\text {th }}\right.$ Edition). Newark, NJ: LexisNexis.

Attrill, G., \& Liell, G. (2007). Offenders views on risk assessment. In N. Padfield (Ed.) Who to release? parole, fairness and criminal justice (pp. 191-201). Cullompton, UK: Willan.

Braithwaite, E., Charette, Y., Crocker, A. G., \& Reyes, A. (2010). The predictive validity of clinical ratings of the Short-Term Assessment of Risk and Treatability (START). International Journal of Forensic Mental Health, 9, 271-281.

Bremer, J. F. (2001). Protective Factors Scale: Determining the level of intervention for youth with harming sexual behavior. St. Paul, MN: Project Pathfinder.

Burnett, R., \& Maruna, S. (2006). The kindness of prisoners: Strength-based resettlement in theory and in action. Criminology and Criminal Justice, 6, 83-106.

Coan, J. (2010). Attachment and the brain. Journal of Social and Personal Relationships, 27, 210-217.

Cochran, J. K., Wood, P. B., \& Arneklev, B. J. (1994). Is the religiositydelinquency relationship spurious? A test of arousal and social control theories. Journal of Research in Crime and Delinquency, 31, 92-123.

Chu, C. M., Thomas, S. D., Ogloff, J. R., \& Daffern, M. (2011). The predictive validity of the Short-Term Assessment of Risk and Treatability (START) in a secure forensic hospital: Risk factors and strengths. International Journal of Forensic Mental Health, 10, 337345. 
De Jong, P., \& Berg, I. K. (2008). Interviewing for solutions ( $3^{\text {rd }}$ Edition). Belmont, CA: Thompson Brooks.

De Ruiter, C., \& Nicholls, T. L. (2011). Protective factors in forensic mental health: A new frontier. International Journal of Forensic Mental Health, 10, 160-170.

De Vogel, V., De Ruiter, C., Bouman, Y., \& De Vries Robbé, M. (2009). SAPROF: Guidelines for the assessment of protective factors for violence risk. English version. Utrecht, The Netherlands: Forum Educatief.

De Vogel, V., De Ruiter, C., Bouman, Y., \& De Vries Robbé, M. (2012). SAPROF: Guidelines for the assessment of protective factors for violence risk. $2^{\text {nd }}$ Edition. Utrecht, The Netherlands: De Forensische Zorgspecialisten.

De Vries Robbé, M., \& De Vogel, V. (2012). Research chapter to the SAPROF $2^{\text {nd }}$ Edition manual. Utrecht, The Netherlands: Van der Hoeven Kliniek.

De Vries Robbé, M., De Vogel, V., \& De Spa, E. (2011). Protective factors for violence risk in forensic psychiatric patients: A retrospective validation study of the SAPROF. International Journal of Forensic Mental Health, 10, 178-186.

De Vries Robbé, M., De Vogel, V., Koster, K., \& Bogaerts, S. (submitted). Assessing protective factors for sexually violent offending: The value of the SAPROF.

Farmer, M., Beech, A. R., \& Ward, T. (2012). Assessing desistance in child sexual abusers: A qualitative study. Journal of Interpersonal Violence, 27, 930-950.

Farrall, S. (2004). Social capital and offender re-integration: Making probation desistance focused. In S. Maruna \& R. Immarigeon (Eds.) 
After Crime and Punishment: Pathways to Offender Reintegration (pp. 57-84). Cullompton, Devon: Willan.

Farrall, S., \& Calverley, A. (2005). Understanding Desistance from Crime: New Theoretical Directions in Resettlement and Rehabilitation. Milton Keynes: Open University Press.

Farrington, D. P. (2003). Developmental and life-course criminology: Key theoretical and empirical issues - The 2002 Sutherland Award Address. Criminology, 41, 221-255.

Fishbein, M., \& Azjen, I. (2010). Predicting and changing behaviour: The reasoned action approach. New York: Psychology Press.

Gendreau, P., Smith, P., \& French, S. (2006). The theory of effective correctional intervention: Empirical status and future directions. Taking stock: The status of criminological theory, 15, 419-446.

Griffin, H., Beech, A. R., Print, B., Bradshaw, H., \& Quayle, J. (2008). The development and initial testing of the AIM-2 framework to assess risk and strengths in young people who sexually offend. Journal of Sexual Aggression, 14, 211-225.

Herrenkohl, T. I., Hill, K. G., Chung, I. J., Guo, J., Abbott, R. D., \& Hawkins, J. D. (2003). Protective factors against serious violent behavior in adolescence: A prospective study of aggressive children. Social Work Research, 27, 179-191.

Laub, J., \& Sampson, R. (2001). Understanding desistance from crime. Crime and Justice: A Review of Research, 28, 1-70.

Laws, D. R., \& Ward, T. (2010). Desistance from sex offending: Alternatives to throwing away the keys. Guilford Press. 
LeBel, T. P., Burnett, R., Maruna, S., \& Bushway, S. (2008). The 'chicken and egg' of subjective and social factors in desistance from crime. European Journal of Criminology, 5, 131-159.

Lodewijks, H. P. B., de Ruiter, C., \& Doreleijers, T. H. A. (2010). The impact of protective factors in desistance from violent offending: A study in three samples of adolescent offenders. Journal of Interpersonal Violence, 25, 568-587.

Mann, R. E., Hanson, R. K., \& Thornton, D. (2010). Assessing risk for sexual recidivism: Some proposals on the nature of psychologically meaningful risk factors. Sexual Abuse: A Journal of Research and Treatment, 22, 191-217.

Maruna, S. (2001). Making good: How ex-convicts reform and rebuild their lives. Washington, DC: American Psychological Association Books.

Maruna, S., \& LeBel, T. (2003). Welcome home? Examining the "re-entry court" concept from a strengths-based perspective. Western Criminology Review, 4, 91-107.

McNeill, F. (2006). A desistance paradigm for offender management. Criminology and criminal Justice, 6, 39-62.

Miller, H. A. (2006). A dynamic assessment of offender risk, needs, and strengths in a sample of pre-release general offenders. Behavioral Sciences \& the Law, 24, 767-782.

Petry, N. M., Tedford, J., \& Martin, B. (2001). Reinforcing compliance with non-drug-related activities. Journal of substance abuse treatment, $20,33-44$.

Print, B., Griffin, H., Beech, A., Quayle, J., Bradshaw, H., Henniker, J., \& Morrison, T. (2007). AIM2. An initial assessment model for young people who display sexually harmful behaviour. Manchester: The AIM Project. 
Robinson, G., \& Shapland, J. (2008). Reducing recidivism a task for restorative justice? British Journal of Criminology, 48, 337-358.

Rogers, R. (2000). The uncritical acceptance of risk assessment in forensic practice. Law and Human Behavior, 24, 595-605.

Serin, R. C., \& Lloyd, C. (2009). Examining the process of offender change: The transition to crime desistance. Psychology, Crime \& Law, 15, 347-364.

Toch, H. (2000). Altruistic activity as correctional treatment. International Journal of Offender Therapy and Comparative Criminology, 44, 270278.

Uggen, C., \& Janikula, J. (1999). Volunteerism and arrest in the transition to adulthood. Social Forces, 78, 331-262.

Ullrich, S., \& Coid, J. (2011). Protective factors for violence among released prisoners: Effects over time and interactions with static risk. Journal of Consulting and Clinical Psychology, 79, 381-390.

Viljoen, S., Nicholls, T., Greaves, C., Ruiter, C., \& Brink, J. (2011). Resilience and successful community reintegration among female forensic psychiatric patients: a preliminary investigation. Behavioral Sciences \& the Law, 29, 752-770.

Wand, T. (2010). Mental health nursing from a solution focused perspective. International Journal of Mental Health Nursing, 19, 210-219.

Ward, T., \& Beech, A. R. (2005). An integrated theory of sexual offending. Aggression and Violent Behavior, 11, 44-63.

Ward, T., \& Brown, M. (2004). The Good Lives Model and conceptual issues in offender rehabilitation. Psychology, Crime \& Law, 10(3), 243-257.

Ward, T., \& Mann, R. E. (2004). Good Lives and the rehabilitation of offenders: A positive approach to sex offender treatment. In P. A. 
Linley \& S. Joseph (Eds.), Positive Psychology in Practice (pp. 598616). Hoboken, NJ: Wiley.

Warr, M. (1998). Life course transitions and desistance from crime. Criminology, 36, 183-216.

Webster, C. D., Martin, M. L., Brink, J., Nicholls, T. L., \& Middleton, C. (2004). Manual for the Short Term Assessment of Risk and Treatability (START) (Version 1.0 Consultation Edition). Port Coquitlam, Canada: Forensic Psychiatric Services Commission and St. Joseph's Healthcare.

Zamble, E., \& Quinsey, V. L. (1997). The Process of Criminal Recidivism. University of Cambridge Press. 
Table 1. Established and Promising Risk Factors for Sexual Offending and their Corresponding Healthy Poles

\begin{tabular}{|c|c|}
\hline Risk Factor & Corresponding Healthy Pole \\
\hline Sexual preoccupation & $\begin{array}{l}\text { Moderate intensity sexual drive } \\
\text { A preference for having sex with someone you are emotionally attached to and who is } \\
\text { attached to you. Romantic or emotionally intimate connection is seen as being as desirable } \\
\text { as sexual gratification. }\end{array}$ \\
\hline Deviant sexual interest & $\begin{array}{l}\text { Sexual preference for consenting adults } \\
\text { A preference for sex with consenting sexual partners of adult age. Desire for potentially } \\
\text { reciprocal sexual activities in which the adult partner is more likely than not to also be } \\
\text { interested in the activity. }\end{array}$ \\
\hline Offence-supportive attitudes & $\begin{array}{l}\text { Attitudes supportive of respectful and age-appropriate sexual relationships } \\
\text { Weighs the rights of others equally with own wants and desires. Recognizes the right to } \\
\text { refuse sexual activity and opposes sexual abuse. Recognizes the nature of childhood and } \\
\text { the implications of emotional \& physical immaturity for likely harm that would be caused } \\
\text { by early sexual activity. }\end{array}$ \\
\hline $\begin{array}{l}\text { Emotional congruence with } \\
\text { children }\end{array}$ & $\begin{array}{l}\text { Preference for emotional intimacy with adults } \\
\text { Recognizes the nature of childhood developmental stages and the more limited capacity of } \\
\text { children in relation to adult-oriented constructs such as reciprocal emotional intimacy. }\end{array}$ \\
\hline $\begin{array}{l}\text { Lack of emotionally intimate } \\
\text { relationships with adults }\end{array}$ & $\begin{array}{l}\text { Capacity for lasting emotionally intimate relationships with adults } \\
\text { Has one or more emotional confidantes; has lasting intimate relationships including sexual } \\
\text { relationships; can maintain a stable relationship for longer period of time; relationships } \\
\text { are characterized by mutual disclosure of vulnerability and acceptance of each other's } \\
\text { faults. Secure attachment style; sustained emotionally intimate marital type relationships; } \\
\text { emotionally intimate friendships; cooperative and discriminating approach to casual social } \\
\text { / work contacts. }\end{array}$ \\
\hline $\begin{array}{l}\text { Lifestyle impulsiveness } \\
\text { (poor self regulation, impulsive } \\
\text { and reckless, unstable work } \\
\text { patterns) }\end{array}$ & $\begin{array}{l}\text { Self-control } \\
\text { Able to set and achieve medium and long term goals through effortful goal-directed } \\
\text { actions. Considers consequences before taking decisions, and weighs consequences to } \\
\text { others at least as highly as consequences to self. Values pro-social solutions and seeks to } \\
\text { achieve peaceful resolutions of difference rather than aggressive resolutions. Regulating } \\
\text { immediate impulses, stress reactions, and general lifestyle. }\end{array}$ \\
\hline Poor cognitive problem solving & Effective problem solving skills \\
\hline
\end{tabular}




\begin{tabular}{|c|c|}
\hline & $\begin{array}{l}\text { Able to articulate different solutions to a problem, including pro-social solutions, and } \\
\text { choose between solutions by considering the consequences, to self and others, of each } \\
\text { option. Weights long term gain over short term gain. }\end{array}$ \\
\hline $\begin{array}{l}\text { Resistance to rules and } \\
\text { supervision }\end{array}$ & $\begin{array}{l}\text { Acceptance of rules and supervision } \\
\text { Capacity to connect with people in authority. Meaningful relationships with supervising or } \\
\text { treating professionals. Able to accept rules and regulations and keep to agreements with } \\
\text { treatment staff, employers, probation officers and other professionals. Manages to obey } \\
\text { imposed legal conditions. }\end{array}$ \\
\hline Grievance/hostility & $\begin{array}{l}\text { Trustful and forgiving orientation } \\
\text { An orientation to others that is typically trustful and peaceful, seeing the others' point of } \\
\text { view/perspective, preferring peaceful solutions to interpersonal conflict and generally } \\
\text { able to offer forgiveness after being wronged. }\end{array}$ \\
\hline Negative social influences & $\begin{array}{l}\text { Law-abiding social network } \\
\text { Social network primarily or entirely composed of stable, law-abiding individuals who } \\
\text { promote pro-social activity and who offer support and strengthen self-control. }\end{array}$ \\
\hline Hostility towards women & $\begin{array}{l}\text { Positive attitudes towards women } \\
\text { Generally pro-social, trusting and respectful attitudes towards women. Views women as } \\
\text { equal to men. Believes women have good intentions. }\end{array}$ \\
\hline Machiavellianism & $\begin{array}{l}\text { Honest and respectful attitudes } \\
\text { Views others as equal. Recognizes others' abilities and strengths. Values honesty and does } \\
\text { not take advantage of others. }\end{array}$ \\
\hline $\begin{array}{l}\text { Lack of concern for others / } \\
\text { Callousness }\end{array}$ & $\begin{array}{l}\text { Empathy } \\
\text { Shows interest in others. Cares about other people's feelings and well-being. Attempts to } \\
\text { help others when in need. Does not act upon own needs before considering those of } \\
\text { others. }\end{array}$ \\
\hline Dysfunctional coping & $\begin{array}{l}\text { Functional coping } \\
\text { Dealing with negative emotions (like anger, anxiety or rejection) through appropriate, } \\
\text { socially acceptable strategies. Managing stress in a calm, non-sexual and effective } \\
\text { manner. }\end{array}$ \\
\hline
\end{tabular}


Table 2. Protective Factors of the AIM-2 and the SAPROF and the Best Predictors for Sexual Offenders

\begin{tabular}{|c|c|}
\hline AIM-2 & SAPROF \\
\hline $\begin{array}{l}\text { Referral behavior appears to be } \\
\text { experimental (or non-abusive) }\end{array}$ & Intelligence \\
\hline $\begin{array}{l}\text { Abusive behavior appears to be peer } \\
\text { influenced }\end{array}$ & Secure attachment in childhood \\
\hline $\begin{array}{l}\text { Abusive behavior ceased when victim } \\
\text { demonstrated non-compliance / distress }\end{array}$ & Empathy \\
\hline $\begin{array}{l}\text { Accepts responsibility for the referral } \\
\text { offense (low level of denial) }\end{array}$ & Coping* \\
\hline $\begin{array}{l}\text { Young person regrets having sexually } \\
\text { offended }\end{array}$ & Self-control* \\
\hline $\begin{array}{l}\text { Willing to address sexual behavior } \\
\text { problems }\end{array}$ & Work $^{*}$ \\
\hline Healthy physical developmental history & Leisure activities* \\
\hline Average / above average intelligence* & Financial management* \\
\hline $\begin{array}{l}\text { Positive talents and / or leisure } \\
\text { interests* }\end{array}$ & Motivation for treatment* \\
\hline $\begin{array}{l}\text { Good negotiation / problem solving } \\
\text { skills }\end{array}$ & Attitudes towards authority* \\
\hline $\begin{array}{l}\text { Developmentally appropriate level of } \\
\text { sexual knowledge }\end{array}$ & Medication* \\
\hline Positive realistic goals / plans & Network* $^{*}$ \\
\hline Good communication skills & Intimate relationship \\
\hline $\begin{array}{l}\text { Grown up with consistent and positive } \\
\text { relationship with at least one adult }\end{array}$ & Professional care* \\
\hline $\begin{array}{l}\text { The most significant adults in a young } \\
\text { person's life demonstrate good } \\
\text { protective attitudes and behaviors* }\end{array}$ & Living situation \\
\hline $\begin{array}{l}\text { The most significant adults in a young } \\
\text { person's life demonstrate positive } \\
\text { emotional coping strategies* }\end{array}$ & External control \\
\hline \multicolumn{2}{|l|}{$\begin{array}{l}\text { The most significant adults in a young } \\
\text { person's life have a support network }\end{array}$} \\
\hline \multicolumn{2}{|l|}{$\begin{array}{l}\text { The most significant adults in a young } \\
\text { person's life are generally healthy }\end{array}$} \\
\hline \multicolumn{2}{|l|}{$\begin{array}{l}\text { The young person uses at least one } \\
\text { emotional confidant* }\end{array}$} \\
\hline \multicolumn{2}{|l|}{$\begin{array}{l}\text { Positive evaluations from work / } \\
\text { educational staff* }\end{array}$} \\
\hline Positive relationships with & \\
\hline
\end{tabular}




\begin{tabular}{|l|l|}
\hline professionals* & \\
\hline $\begin{array}{l}\text { Young person feels emotionally and } \\
\text { physically safe within their current } \\
\text { environment }\end{array}$ & \\
\hline $\begin{array}{l}\text { Makes positive use of social support } \\
\text { network }\end{array}$ & \\
\hline $\begin{array}{l}\text { Current carers / living environment can } \\
\text { maintain appropriate level of } \\
\text { supervision }\end{array}$ & \\
\hline
\end{tabular}

* = Best predicting factors for sexual offenders based on studies by Griffin et al. (2008) and De Vries Robbé et al. (submitted). 
Table 3. Protective Factors Evidence for Sexual Offenders

\begin{tabular}{|c|c|c|c|c|c|c|c|c|}
\hline \multirow[t]{2}{*}{ Evidence } & \multicolumn{8}{|c|}{ Proposed protective domains } \\
\hline & 1 & 2 & 3 & 4 & 5 & 6 & 7 & 8 \\
\hline \multicolumn{9}{|l|}{ Healthy poles of risk factors } \\
\hline Moderate intensity sexual drive & $\mathrm{x}$ & & & & & & & \\
\hline Sexual preference for consenting adults & $\mathrm{x}$ & & & & & & & \\
\hline $\begin{array}{l}\text { Attitudes supportive of respectful and } \\
\text { age-appropriate sexual relationships }\end{array}$ & $x$ & & & & & & & \\
\hline $\begin{array}{l}\text { Preference for emotional intimacy with } \\
\text { adults }\end{array}$ & & $\mathrm{x}$ & & & & & & \\
\hline $\begin{array}{l}\text { Capacity for lasting emotionally intimate } \\
\text { relationships with adults }\end{array}$ & & $x$ & & & & & & \\
\hline Self-control & & & & $\mathrm{x}$ & & & $\mathrm{x}$ & \\
\hline Effective problem solving skills & & & & & $\mathrm{x}$ & & & \\
\hline Acceptance of rules and supervision & & & $x$ & & & & & \\
\hline Trustful and forgiving orientation & & $\mathrm{x}$ & & & & & & \\
\hline Law-abiding social network & & & $\mathrm{x}$ & & & & & \\
\hline Positive attitudes towards women & & $\mathrm{x}$ & & & & & & \\
\hline Honest and respectful attitudes & & $\mathrm{x}$ & $\mathrm{x}$ & & & & & \\
\hline Empathy & & $\mathrm{x}$ & $\mathrm{x}$ & & & & & \\
\hline Functional coping & & & & & $\mathrm{x}$ & & & \\
\hline \multicolumn{9}{|l|}{ Desistance factors } \\
\hline Enhanced sense of personal agency & & & & $\mathrm{X}$ & & & & \\
\hline Stronger internal locus of control & & & & $x$ & & & & \\
\hline $\begin{array}{l}\text { Find positive outcomes from negative } \\
\text { events }\end{array}$ & & & & & & & & $\mathrm{x}$ \\
\hline Treatment as turning point & & & $\mathrm{x}$ & & & & & $\mathrm{x}$ \\
\hline $\begin{array}{l}\text { Place within a social group or network: } \\
\text { family, friends and church. }\end{array}$ & & & $\mathrm{x}$ & & & & & \\
\hline \multicolumn{9}{|l|}{ Protective factors tools } \\
\hline Above average intelligence & & & & & $\mathrm{x}$ & & & \\
\hline Positive talents / leisure interests & & & & & & $\mathrm{x}$ & & \\
\hline $\begin{array}{l}\text { Significant network members have } \\
\text { positive attitudes }\end{array}$ & & & $\mathrm{x}$ & & & & & \\
\hline $\begin{array}{l}\text { Significant network members have } \\
\text { positive emotional coping }\end{array}$ & & & $\mathrm{x}$ & & & & & \\
\hline At least one emotional confidant & & & $\mathrm{x}$ & & & & & \\
\hline Positive evaluations from work/education & & & & & & $x$ & & \\
\hline Positive relationships with professionals & & & $\mathrm{x}$ & & & & & \\
\hline Coping & & & & & $x$ & & & \\
\hline Self-control & & & & $\mathrm{x}$ & & & $x$ & \\
\hline Motivation for treatment & & & $\mathrm{x}$ & & & & & $\mathrm{x}$ \\
\hline Attitudes towards authority & & & $\mathrm{x}$ & & & & & \\
\hline Professional care & & & $\mathrm{x}$ & & & & & \\
\hline Medication & & & & & & & & $\mathrm{x}$ \\
\hline Work & & & & & & $\mathrm{x}$ & & \\
\hline
\end{tabular}




\begin{tabular}{|l|c|}
\hline Financial management & $\mathrm{x}$ \\
\hline Leisure activities & $\mathrm{x}$ \\
\hline Network & $\mathrm{x}$ \\
\hline
\end{tabular}

Note. The 8 proposed protective domains for sexual offenders:

1. Healthy sexual interests

2. Capacity for emotional intimacy

3. Constructive social and professional support network

4. Goal directed living

5. Good problem solving

6. Busy with employment or constructive leisure activities

7. Sobriety

8. Hopeful, optimistic and motivated attitude to desistance 